\title{
An Investigation on Graphene and Nanoclay Effects on Hybrid Nanocomposites Post Fire Dynamic Behavior
}

\author{
Antonio Ferreira Ávila ${ }^{a} *$, Eder Cesar Dias ${ }^{\mathrm{b}}$, Diego Thadeu Lopes da Cruz ${ }^{\mathrm{b}}$, Maria Irene Yoshida, \\ Alexandre Queiroz, Bracarense ${ }^{\mathrm{a}}$, Maria Gabriela Reis Carvalho ${ }^{\mathrm{b}}$,José de Ávila Junior ${ }^{\mathrm{b}}$ \\ ${ }^{a}$ Deparment of Mechanical Engineering, \\ Graduate Studies Program in Mechanical Engineering, \\ Universidade Federal de Minas Gerais - UFMG, \\ Antonio Carlos Avenue, 6627, CEP 31270-901 Belo Horizonte, MG, Brazil \\ ${ }^{\mathrm{b}}$ Graduate Studies Program in Mechanical Engineering, \\ Universidade Federal de Minas Gerais - UFMG, \\ Antonio Carlos Avenue, 6627, CEP 31270-901 Belo Horizonte, MG, Brazil \\ ${ }^{\mathrm{c}}$ Deparment of Chemistry, Universidade Federal de Minas Gerais - UFMG, \\ Antonio Carlos Avenue, 6627, CEP 31270-901 Belo Horizonte, MG, Brazil
}

Received: July 8, 2009; Revised: February 15, 2010

\begin{abstract}
This paper deals with the post fire behavior of hybrid nanocomposites under dynamic loadings. A series of tests were performed to investigate how nanoparticles (i.e. nanoclay and graphene nanosheets) affect the post-fire overall composite behavior. Carbon fiber/epoxy-nanoclay and carbon fiber/epoxy-graphene nanosheets were manufactured. The nanoparticles employed were Cloisite 30B nanoclay, and surface modified graphene nanosheets. The epoxy system used was RemLam M/HY956. The nanocomposites were made using ultrasonic mixer for nanoparticle dispersion in acetone followed by a shear mixing of acetone/nanoparticle/hardener. The following steps involved degassing, the addition of resin to the mixture and, the hand lay-up with vacuum assisted cure. Thermo gravimetric analysis (TGA) indicates an average decrease on peak mass loss around $41 \%$ with the addition of small amount of nanoparticles. The sample plates were exposed to a heat flux of $800 \mathrm{~kW} \cdot \mathrm{m}^{-2}$ for a period up to 120 seconds. The post-fire low velocity impact tests indicated the impact resistance degraded as a function of heat exposure. However, the addition of nanoclay leads to an increase on impact peak force of $11.69 \%$. The carbon oxidation could be the main cause of the increase on impact peak load is lower than expected, only $6.72 \%$. The model predictions are overestimated by approximately $8 \%$. Even though, it can be a good tool for composites design.
\end{abstract}

Keywords: nanocomposites, graphene nanosheets, nanoclay, heat exposure

\section{Introduction}

As mentioned by Ulven and Vaidya ${ }^{1}$, the reduction of structural integrity during or after fire exposure has been assessed by measuring mechanical property loss, i.e. tensile, compression and flexural properties. One of the most comprehensive studies on fire effect on polymeric matrix composites (PMC), in special glass-reinforced composites, was performed by Mouritz et al. ${ }^{2-5}$. In addition to performing a meticulous experimental investigation, they also proposed a series of mathematical models to predict the mechanical properties of the composites after fire exposure. Since their focus was on naval transportation, their research projects were restricted to glass-reinforced polyester composites.

As discussed by Gibson et al. ${ }^{6}$, the regulations involving fire performance vary according to the type of application. The United States Navy, for example, imposed that a composite structure on fire must retain high stiffness and strength for at least 30 minutes (1800 seconds), when exposed to a continuous heat flux of $50 \mathrm{~kW} \cdot \mathrm{m}^{-2}$. In the aeronautical industry, due to the nature of airplanes, this period is reduced to just a few minutes. As stated by Kim et al. ${ }^{7}$, the railroad regulations concerning fire focus is based on three main issues, i.e. flame propagation, fume toxicity and smoke generation. In their large scale tests, the flames in the composite train car body interior were extinguished in around 5 minutes (290 seconds). According to Hernangil et al. ${ }^{8}$, in all cases, the study of the fire behavior should take into consideration two main factors: the material reaction to fire and the products generated during combustion. This concern derives from the fact that smoke emissions formed due to incomplete combustion are also threatening to human life.

During the composite materials exposure to fire, four stages can be observed. The first one is the heating stages, when the polymer is heated by an external heat source; the heating stage is followed by a decomposition stage, when polymer chains are broken and free radicals are liberated; then the flammable gases mixed with atmospheric oxygen are ignited by a heat source; the final stage is the flame spreading due to the exothermic combustion. As recognized by Gu and Asaro ${ }^{9}$, it is a well known fact that composites can be severely degraded under thermal loading caused by fire. The reduction in 
stiffness due to degradation by fire reduces the load carrying capacity of the composites, and this can lead to structural failure under what are thought to be normally safe operational loads. Therefore, the design of composite structures that can be subjected to fire conditions must be considered.

It is a common practice among composite designers, to add flame retardants (FR) to ensure safety to fire. As described by Guo et al. ${ }^{10}$, the halogenated flame retardants, e.g. organic brominates compounds, are often used to improve FR properties of polymers. However, they usually increase both smoke and carbon monoxide yield rates formed due to incomplete combustion. Two other options for flame retardants are aluminum trihydrate and magnesium hydroxide, also called intumescent systems. A drawback of these intumescent systems is the high loading of filler within the polymer matrix. Loading levels of more than $60 \mathrm{wt}$. (\%) are usually required to achieve a proper FR property. Guo et al. ${ }^{10}$ report a shift away from the use of conventional flame retardants due to environmental concerns and the disadvantages mentioned above. A new approach for improving the FR properties of polymers is the use of layered silicate nanoparticles (i.e., clay), such as organically modified montmorillonite (MMT).

As stated by Morgan ${ }^{11}$, it is widely accepted that there are four advantages offered by nanocomposites formation: improvements in fire retardancy, an increase in heat distortion temperature, improvement in flexural modulus, and a decrease in permeability. $\mathrm{He}$ also reported impressive improvements in flammability, with reductions in peak heat release rate (PHRR) of 40 to $65 \%$ at very low loadings of layered silicate. To investigate the nanoclay effect as FR additives, $\mathrm{Koo}^{12}$ used two types of nanoclay, i.e. Cloisite 15A and 20A from Southern ${ }^{\circledR}$ Clay Products. The baseline polymer selected was Petrothene ${ }^{\circledR}$ XL 07414, a nonhalogenated, nontarnishing, FR-crosslinkable polyolefin copolymer containing approximately $40 \%$ of alumina trihydrate. An intumescent FR additive based on ammonium polyphosphate, i.e. Clariant Exolit AP 750, was also used by Koo in his study. By varying the nanoclay content up to 8 wt. (\%) and employing a mass loss calorimeter for flammability tests, Koo detected a decrease on peak heat release rate with the increase of nanoclay content. By adding the AP 750 to the nanocomposite a delay on ignition time was observed. The improved performance of Cloisite $15 \mathrm{~A}$ relative to Cloisite $20 \mathrm{~A}$ can was attributed to difference in the surface treatment of the two nanoclays. Another comprehensive investigation on nanoparticles effects performed by $\mathrm{Koo}^{12}$ involved a different class of polymer, i.e. polyamide 11 (PA11). In this case, in addition to two nanoclays (Cloisite 30B and Cloisite 93A), Koo also used nanosilica and carbon nanofibers (CNF). The nanoclay contents were selected as $2.5,5,7.5$ and 10 wt. (\%), the carbon nanofibers were selected as 1, 3 and $5 \mathrm{wt}$. (\%), respectively. The nanosilica and nanoclay contents employed by Koo were the same. After exposing the nanocomposites to a $50 \mathrm{KW} \cdot \mathrm{m}^{-2}$ heat flux with a cone calorimeter for 180 seconds, Koo concluded that nanosilica had no effect on the polymer flammability. Furthermore, $10 \mathrm{wt}$. (\%) of Cloisite 30B added to the PA11 lead to a $73 \%$ reduction on peak heat release rate (PHRR) and a reduction on mean $\mathrm{CO}$ yield. The $5 \mathrm{wt}$. (\%) CNF also performed well, it lead to a decrease on peak HRR of $60 \%$; although the mean $\mathrm{CO}$ yield indicated an increase when compared against the neat PA11. As stated by $\mathrm{Koo}^{12}$, the Cloisite 93A data followed the CNF data.

$\mathrm{Li}$ el al. ${ }^{13}$ also investigated another nanoparticle, i.e. antimony oxide $\left(\mathrm{Sb}_{2} \mathrm{O}_{3}\right)$, as flame retardant. According to the authors, $\mathrm{Sb}_{2} \mathrm{O}_{3}$ has long been known as a synergistic agent with halogen, which is widely used as a FR in plastics, rubber, textile, and coatings. However, it has a limited scope due to its large particle size, large load amount, heavier smoke in burning, and lower mechanical properties. To be able to improve the $\mathrm{Sb}_{2} \mathrm{O}_{3}$ nanoparticles performance, they prepared a nano- $\mathrm{Sb}_{2} \mathrm{O}_{3} /$ mica composition through colloidal and assembling techniques. Their good results can be explained by the distribution of nano- $\mathrm{Sb}_{2} \mathrm{O}_{3}$ particles on the mica surface with smaller size (about $5 \mathrm{~nm}$ ), higher levels of dispersion, and narrower size distribution. These characteristics brought as consequence a decrease on the effective temperature and polymer combustion reaction rate. Finally, the char formation also decreased due to the presence of nano- $\mathrm{Sb}_{2} \mathrm{O}_{3} /$ mica.

Morgan et al. ${ }^{14}$ considered the nanoclay effect on polymeric matrix flammability. They focused on two classes of clays, i.e. natural clay (montmorillonite) and synthetic clay fluorinated synthetic mica (FSM). The non-treated (inorganic) and organic-modified form of the two clays were investigated. When the flammability tests were performed into nano-modified polystyrene matrices, the ignition time was reduced in all cases. The worst case, a $63 \%$ reduction on ignition time, was obtained with $10 \mathrm{wt}$. (\%) of inorganic FSM, while the addition of $1.9 \mathrm{wt}$. (\%) of organic modified fluorinated synthetic mica to polystyrene lead to a $3 \%$ ignition time reduction. The montmorillonite (MMT) data seems to follow the same trend. A reduction on ignition time, up to $61.5 \%$ with $10 \mathrm{wt}$. (\%) of inorganic MMT and "quasi-equilibrated" condition when 2 wt. (\%) the organic modified MMT was employed. In both cases, FSM and MMT, a slight increase on HRR, up to $6.25 \%$ with FSM and $3.9 \%$ with MMT was observed by Morgan and his colleagues.

As this paper deals with carbon fibers at high temperature the issue of oxidation must be addressed. According to Wang and coworkers ${ }^{15}$, carbon fibers begin to be oxidized and chemical reactivity at $750 \mathrm{~K}$ in air. That is why many researchers believed that for high temperature applications metal matrix or ceramic matrix composites should be used. However, as discussed by $\operatorname{Keller}^{16}$, when weight and strength are important issues carbon fibers cannot be discarded. To be able to be used in harsh environments carbon fibers must be exposed to a protective coating. In Keller's work, he used a linear polymer poly (carborane-siloxane-acetylene), which in a controlled environment, i.e. a flow of air $(50 \mathrm{cc} / \mathrm{min})$ at $1{ }^{\circ} \mathrm{C} / \mathrm{min}$ to $1000{ }^{\circ} \mathrm{C}$, lead to no significant oxidation. However, when the temperature gradient is higher, the oxidation process cannot be avoided. Different types of coating were tested in the past, e.g. silicon carbide ( $\mathrm{SiC})$ by Hatta et al. ${ }^{17}$, with limited results. According to Jacobson and Curry $^{18}$, the carbon fibers oxidation process is related not only to the type of carbon but it is also associated to reaction kinetics and microstructures. As stated by Jiqiao et al. ${ }^{19}$, different microstructures lead to different levels of porosity. At high temperatures, these porous provide a venue for gases from resin degradation and they are perfect locus for chemical reactions and oxidation. One possible solution for such problem is the addition of nanoparticles to the matrix and fibers. These nanoparticles can reduce the fibers porosity and improve carbon fibers performance at high temperature.

As discussed by Zhang and co-workers ${ }^{20}$, the flammability of polymeric composites was reduced by the addition of small amount of nanoclays (in their case, Cloisite 30B) in conjunction with conventional phosphorus and a hindered amine flame retardants due to the possible phosphorus-nitrogen synergism. The nanoclay effects were not restricted to the matrix, as porous on fibers were reduced with the addition of nanoparticles. An even better result was observed by Liu et al. ${ }^{21}$, they noticed that under oxidative environment the formation of etch pits on graphene nanosheets is dependent on the number of nanosheets. They performed a series of oxidative etching at $200,250,300,400,450,500$, and $600{ }^{\circ} \mathrm{C}$. According to Liu and collaborators $^{21}$, atomic microscopy analysis showed no etching of single-, double-, and triple-layer graphene for oxidation at or below $400{ }^{\circ} \mathrm{C}$. Etch pits $(\sim 20 \mathrm{~nm}$ diameter $)$ were found on single layers at $450{ }^{\circ} \mathrm{C}$, but not on multiple-layer samples even up to $500{ }^{\circ} \mathrm{C}$. 
Therefore, the use of multilayer graphene could be a valuable option for solving or at least reduce carbon fibers oxidation problems.

Up to now, nanoparticles seem to be a valuable option as FR for polymers. However, the effect of graphene nanosheets as another FR option applied to carbon fibers laminate composites has not been completely investigated. This paper deals with carbon fiber-nano modified epoxy systems thick laminates under intense fire. This research focuses on mechanical properties degradation due to fire into carbon fiber-nano modified epoxy composites.

\section{Materials and Experimental Procedures}

Hybrid nanocomposites were manufactured following the procedure described in Ávila et al. ${ }^{22}$. A plain weave fabric of carbon fiber with 220 g. $\mathrm{m}^{-2}$ areal density was used as traditional reinforcement. The epoxy formulation was based on diglycidyl ether of bisphenol A resin (DGBA) and a hardener, triethylenetetramine. The weight mixing ratio suggested by the manufacturer was 100A:20B, and the average viscosity was around $1000 \mathrm{cPs}$. The matrix nano-reinforcement was made by high shear mixing. Two types of nanoparticles, i.e. nanoclay and graphene nanosheets, were employed. The nanoclay was an organically modified montmorillonite in a platelet form, i.e. $10 \mu \mathrm{m}$ long, $1 \mu \mathrm{m}$ wide and $50 \mathrm{~nm}$ thick, i.e. Cloisite 30B from Southern Clay Products, while the surface modified graphene nanosheets (Grafmax HC 11-IQ) was supplied by Nacional Grafite. A dispersant agent, acetone, was employed to improve the mixing process. To be able to disperse nanoparticles into the acetone, an ultrasonic mixer was used. After the ultrasonication, the hardener was mixed to the acetone + nanoparticles blend by shear mixing. The degassing stage was required to eliminate bubbles generated during the shear mixing as well as to eliminate the dispersant agent, i.e. acetone. After this procedure, the hand lay-up with vacuum assisted cure was performed. In previous experiments, the largest amount of graphene nanosheets dispersed into the epoxy system without phase separation was 3 wt. (\%). Therefore, for this study, this value was adopted. Consistent with Morgan 11, the amount of nanoclay employed was 5 wt. (\%). Moreover, the fiber/matrix weight ratio was kept equals to 50/50. Two groups of samples were used in this research. The first group was composed of short beams, $100 \mathrm{~mm}$ long and square cross section of $10 \mathrm{~mm}$ edge and 40 layers. The second group was composed of $10 \mathrm{~mm}$ thick square plates with 40 layers and $100 \mathrm{~mm}$ edge. To be able to evaluate the nanocomposites behavior under fire, a set of carbon fiber-epoxy composites were prepared to serve as comparative basis.

To evaluate the nanocomposite plate behavior under intense heat conditions, an oxyacetylene torch was employed. The test followed the procedure developed by Bahramian et al. ${ }^{23}$. According to Bahramian et al., the hot gas can get to $3000 \mathrm{~K}$ and the heat flux can reach $8000 \mathrm{KW} \cdot \mathrm{m}^{-2}$. In the present case, the heat flux is around $800 \mathrm{KW} \cdot \mathrm{m}^{-2}$, much higher than conventional cone calorimeters. The torch apparatus is described elsewhere ${ }^{24}$. The specimens were located $50 \mathrm{~mm}$ bellow the torch tip in a refractory brick. The times of exposure of each set of short beam hybrid nanocomposite were 60 and 120 seconds. The usage of short beams allowed the understanding and visual inspection of the fire effects through the nanocomposite thickness. The nanocomposite plates were exposed to torch for 30, 60, 90 and 120 seconds. The surface temperature of each sample was measured by a type $\mathrm{K}$ thermocouple right after the heat source was removed.

The mass loss during the fire exposure was measured using the same methodology employed by Ulven and Vaidya ${ }^{1}$, i.e. the mass of each specimen was measured before and after fire exposure. Furthermore, the ratio between the char and the undamaged thicknesses was measured following the methodology proposed by Mouritz and Mathys ${ }^{2}$. They applied digital image correlation measurements, i.e. they measured the specimens' thickness before fire exposure and found a linear correlation between pixels and the thickness. After fire exposure, the specimens were photographed and the digital image was analyzed using a public domain software called ImageJ. Another important parameter evaluated was the surface erosion during the fire exposure. As in Bahramina et al..$^{23}$, the surface erosion was assumed to be the cylindrical shape. A morphological analysis of both the charred surface and the residual nanoparticles in the charred layers was also performed using a scanning electronic microscopy (LEO model 1430VP). In all cases, a gold thin film was placed on the surface of the sample to enable scanning. To be able to correlate all data obtained, a thermo gravimetric analysis (TGA) was also performed. TGA data was collected with a Shimadzu DTG 60 under dynamic air atmosphere, at $10{ }^{\circ} \mathrm{C} / \mathrm{min}$ from 25 to $750{ }^{\circ} \mathrm{C}$.

Once the nanostructured laminate is subjected to fire exposure, the impact resistance test by falling dart can be performed. Following the ASTM D 5628-0125, the dart has a hemispherical nose with a radius of $10.0 \pm 0.1 \mathrm{~mm}$. The specimen is clamped between two rectangular steel plates with $13 \mathrm{~mm}$ thickness with a central circular cutout of $50.0 \pm 0.1 \mathrm{~mm}$, see Figure 1 for more details. As the drop weight tower has a maximum height of $3.0 \mathrm{~m}$, the limiting velocity for the device is $7.67 \mathrm{~m} / \mathrm{s}$. The dart is made of AISI 4330 steel. The additional weight can be assembled individually into the dart leading to a mass variation ranging from 246 to $3414 \mathrm{~g}$. During the impact event, the load-time history is recorded by a data acquisition system with a frequency of $50 \mathrm{kHz}$ rate by an $\mathrm{A} / \mathrm{D}$ data acquisition board. As stated by Found et al. ${ }^{26}$, any digital filtering must be done at a cut-off frequency or below this value, which is in general half of the maximum data acquisition rate. However, as described by Ávila et al. ${ }^{27}$, it is recommended that the cut-off frequency must be $10-15 \%$ of the bandwidth of the data in order to avoid electronic noise. In the present case, after a series of pre-tests, a low-pass digital filtering was selected at $3.5 \mathrm{kHz}$, i.e. $14 \%$ of the maximum bandwidth. In contrast with traditional (LVI) tests performed, the dart is not embraced after the first impact, which allows us evaluate the amount of damage sustained by the plates.

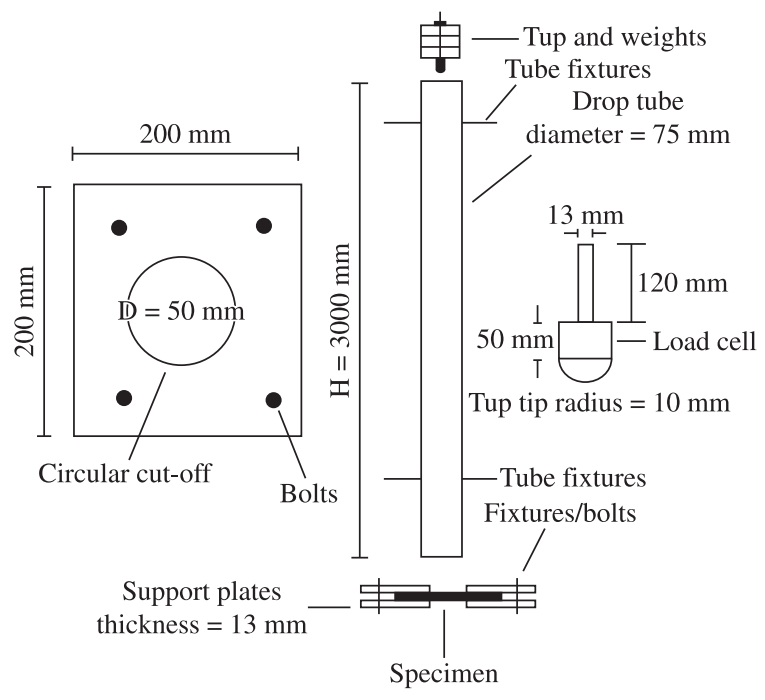

Figure 1. Schematic representation of the low velocity impact device. 


\section{Results and Discussion}

According to Kourtides ${ }^{28}$, a good fire resistant carbon/epoxy composite when submitted to a heat flux around $3.5 \mathrm{KW} . \mathrm{m}^{-2}$ must hold its mechanical and thermal properties for at least 15 minutes. For this research, the time for fire exposure was set equals to 2 minutes, the digital image correlation technique was employed for measuring the burned and unburned regions. Figures 2-4 show the hybrid nanocomposites view section after being exposed to a heat flux of $800 \mathrm{KW} . \mathrm{m}^{-2}$ for 1 and 2 minutes, respectively. It is important to notice that, in this case, the samples exposed to fire were short beams (10 $\mathrm{mm}$ wide, $10 \mathrm{~mm}$ depth, $100 \mathrm{~mm}$ long). As it can be observed in Figures $2 \mathrm{a}$ and $\mathrm{b}$, the hybrid composite without any nanoparticles suffered severe damage with extensive delamination.

The nanoclay presence seems to be beneficial to heat resistance. The same behavior was observed by $\mathrm{Koo}^{12}$ when investigating phenolic resins doped with nanoclay, i.e. MMT nanoclays. Figures $3 \mathrm{a}$ and $\mathrm{b}$ show the char and undamaged regions. In addition to the undamaged region, another region where the char formation is more intense is observed in Figure 3b. It seems that nanoclay acts as a protective barrier against intense heat. This region is represented by the light gray area right below the section damaged by the torch center. Schartel et al. ${ }^{29}$ affirms that the most important feature characterizing combustion is the barrier formation. Still, the increase in melt viscosity as well as the gas permeation reduction can also be attributed to the nanoclay presence. The increase on melt viscosity can be translated into changes in the dripping behavior as the polymer melts. In this case, the dripping behavior was not observed due to the intense heat to which it was exposed. Still, it seems that nanoclay has

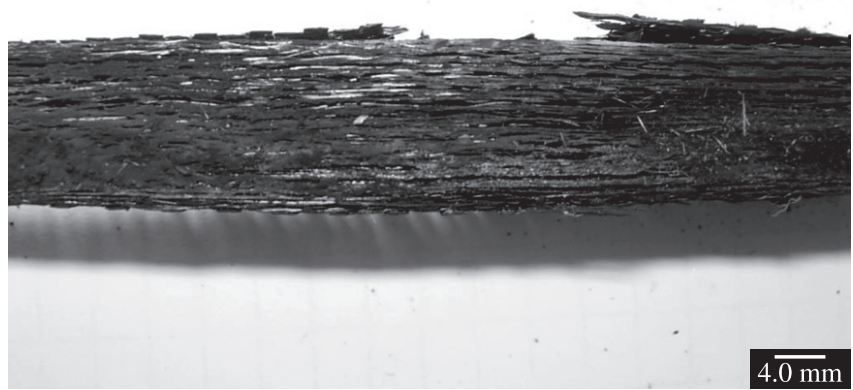

(a)

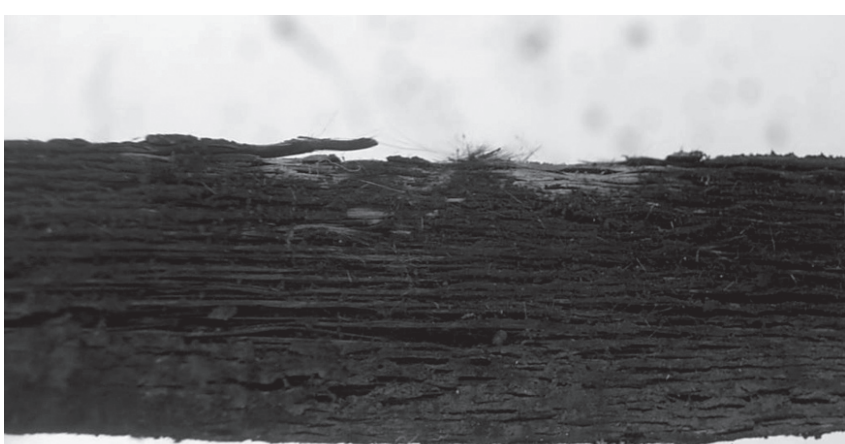

$4.0 \mathrm{~mm}$

(b)

Figure 2. Hybrid nanocomposites side view after fire exposition. a) 1 minute carbon-fiber epoxy; b) 2 minutes carbon-fiber epoxy.

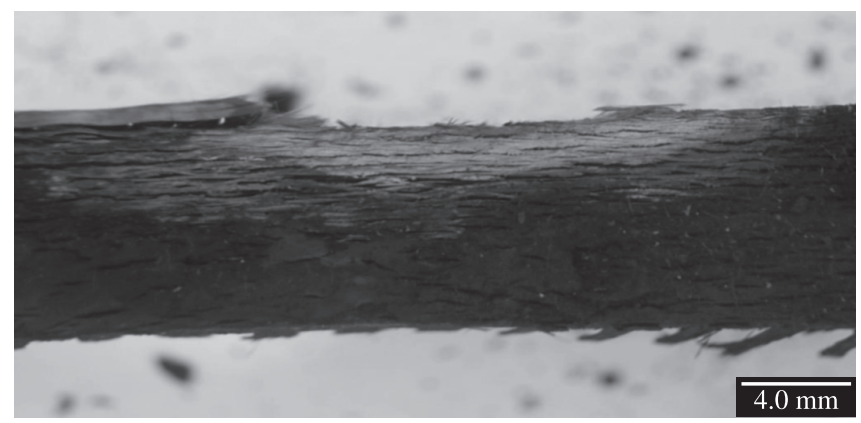

(a)

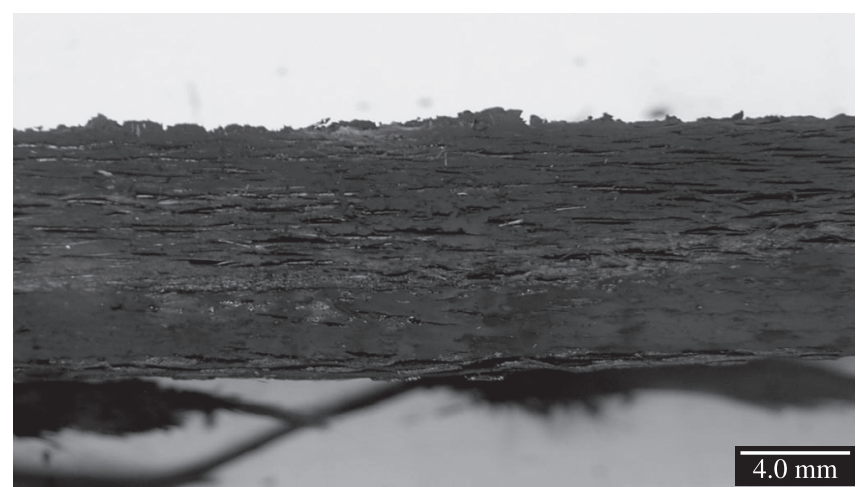

(b)

Figure 3. Hybrid nanocomposites side view after fire exposition. a) 1 minute carbon-fiber epoxy-nanoclay; b) 2 minutes carbon-fiber epoxy-nanoclay.

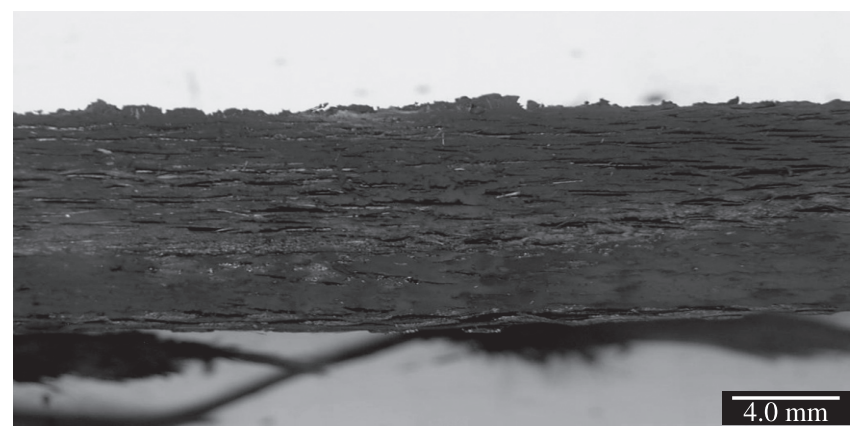

(a)

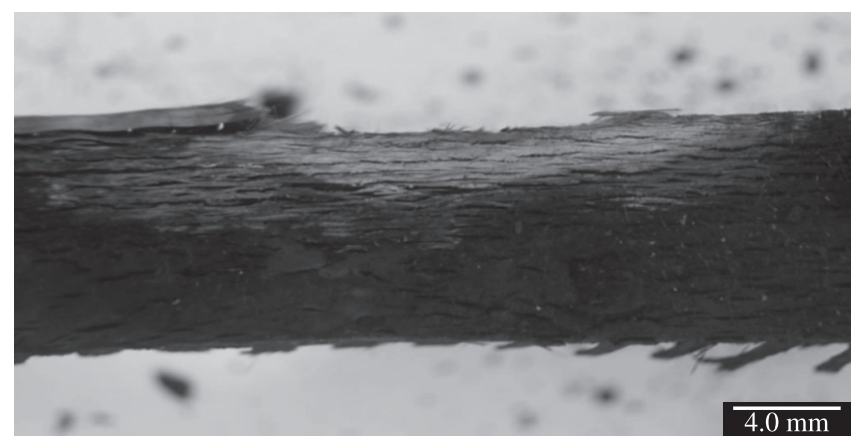

(b)

Figure 4. Hybrid nanocomposites side view after fire exposition. a) 1 minute carbon-fiber epoxy-nanographite; b) 2 minutes carbon-fiber epoxy-nanographite. 
low impact in ignitability. In all tests performed, the ignition time was close to a few seconds due to the intense heat source.

The graphene nanosheets presence inside the epoxy matrix seems to have an influence on the composites' resistance to fire. As it can be observed in Figures $4 \mathrm{a}$ and $\mathrm{b}$, a more pronounced eroded area is present. However, the char layer thickness seems to be less deep than in the other samples. This behavior can be attributed to the graphene nanosheets heat conduction and its natural resistance to heat.

Figure 5 summaries the degradation by fire as a function of time. As it can be noticed, the addition of nanoparticles seems to be beneficial. The char layer for hybrid nanocomposites with graphene nanosheets was the lowest among the three sets of specimens. This can be due to the thermal barrier by the graphene nanosheets after ignition. An important question is how the surface in direct contact with the flame is modified by the intense heat. Figure 6 shows this surface and one can be observed the formation of carbon black in spherical shape that probably acts as a barrier against the resin vapor flow during the heat exposure. Some etch pits are also noted, which it is an indication of oxidation.

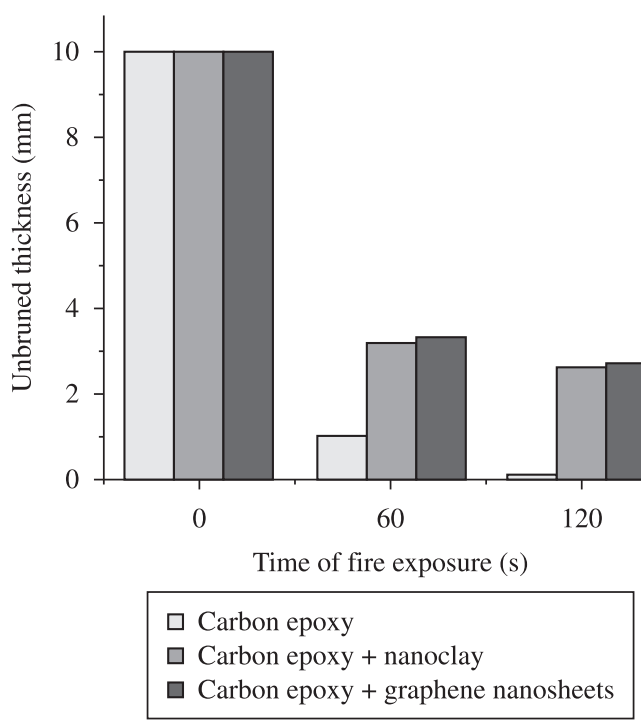

Figure 5. Unburned thickness as a function of time for beam specimens.

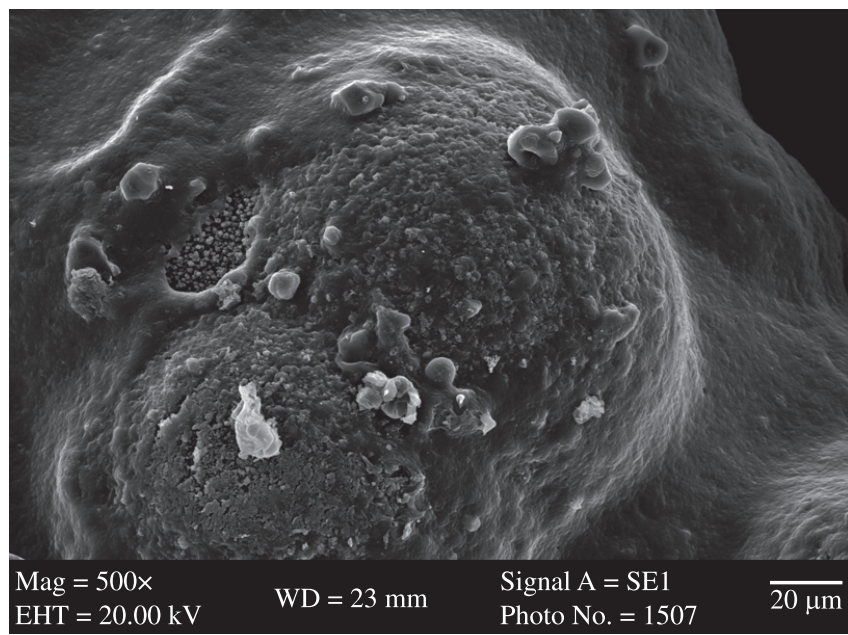

Figure 6. Carbon black formation and etch pits.
A question that naturally arises: Is it possible that some of the nanoparticles remained inside the char layers? To help answer this question, a scanning electron microscope was used. As shown in Figure 7a, the SEM micrographs revealed that resin was vaporized under intense heat exposure. However, the nanoparticles dispersed into the matrix were trapped between the layers. Furthermore, the torch gas flow seems to lead to an agglomeration of the remaining nanoparticles as shown in Figure $7 \mathrm{~b}$. These nanoparticles seem to be fire resistant. Furthermore, they can help explain the char layer thickness reduction, since they can provide a thermal protective barrier. It is worth nothing that, according to Hussain et al..$^{30}$, nanoclays and graphene nanosheets are potential candidates for ablation. The reasons are the thermal barrier formation during combustion and the increase on melting viscosity.

The TGA results are shown in Figures $8 \mathrm{a}-\mathrm{c}$. The addition of nanoparticles, i.e. nanoclay and graphene nanosheets, seems to delay the weight loss. For the pure epoxy system the peak mass loss (indicated by a black arrow) was around $1.04 \mathrm{mg} / \mathrm{min}$, while for the epoxy/nanoclay and epoxy/graphene nanosheets were 0.59 and $0.63 \mathrm{mg} / \mathrm{min}$, respectively. The average decrease on peak mass loss

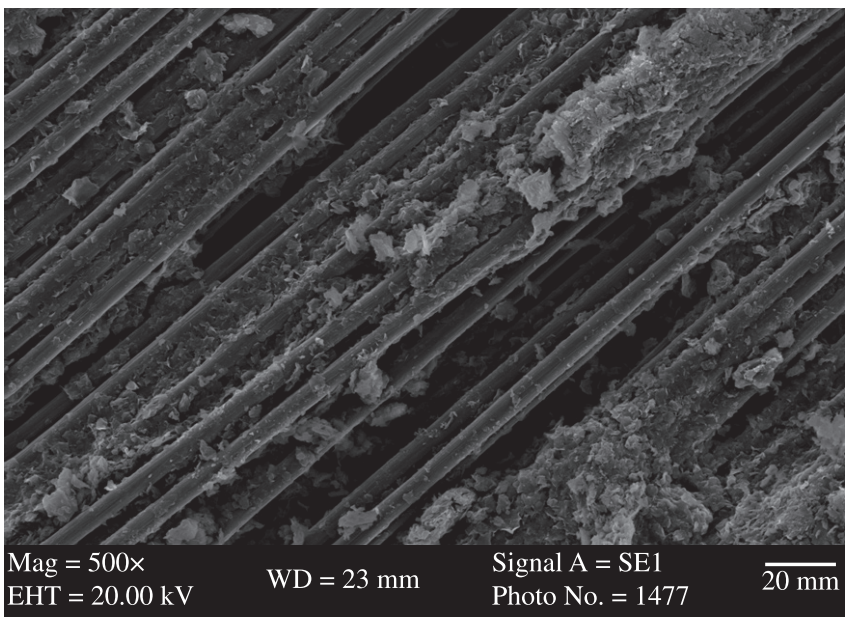

(a)

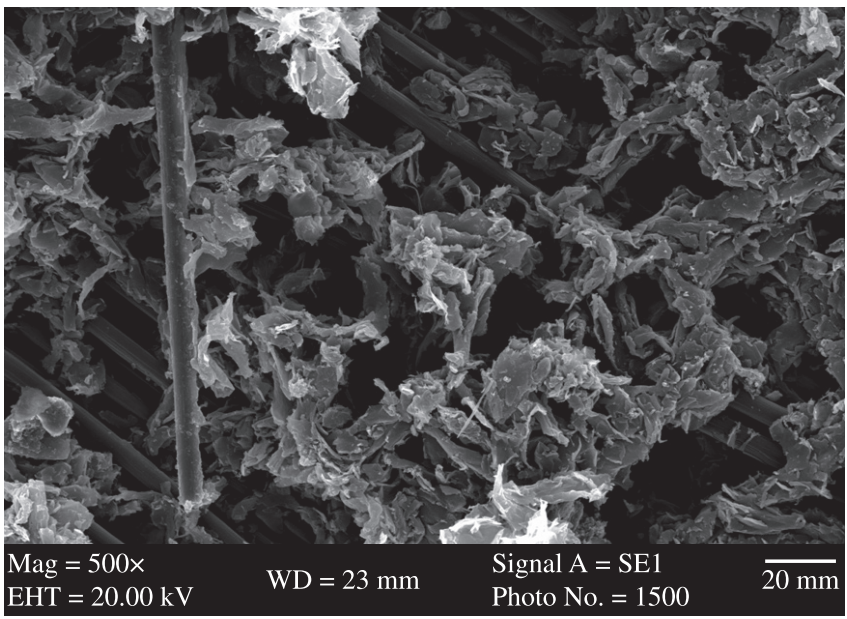

(b)

Figure 7. Nanoparticle presence into char layers. a) Pure epoxy/carbon fiber; b) Nanoparticles-epoxy/carbon fibers. 


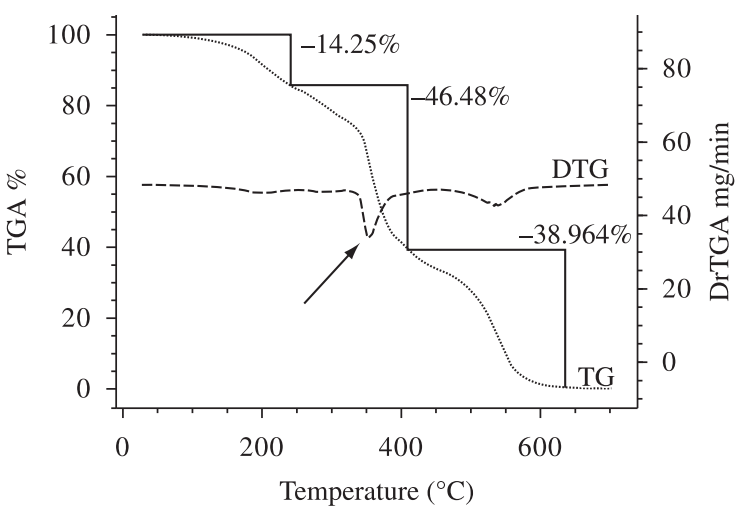

(a)

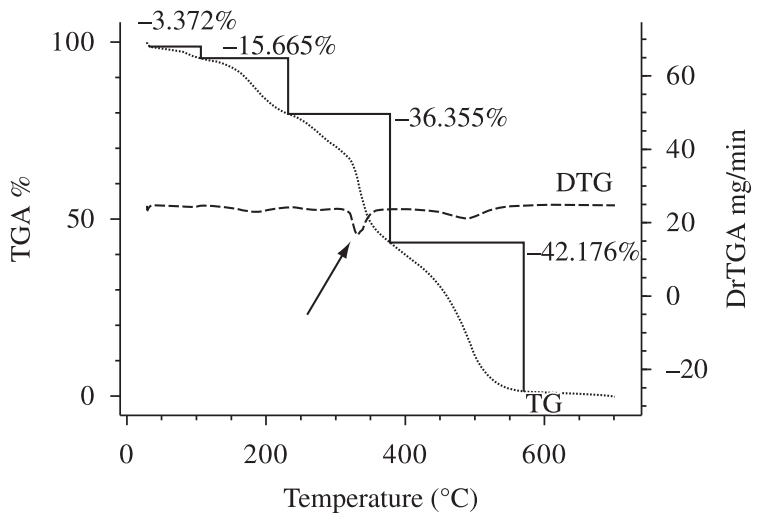

(b)

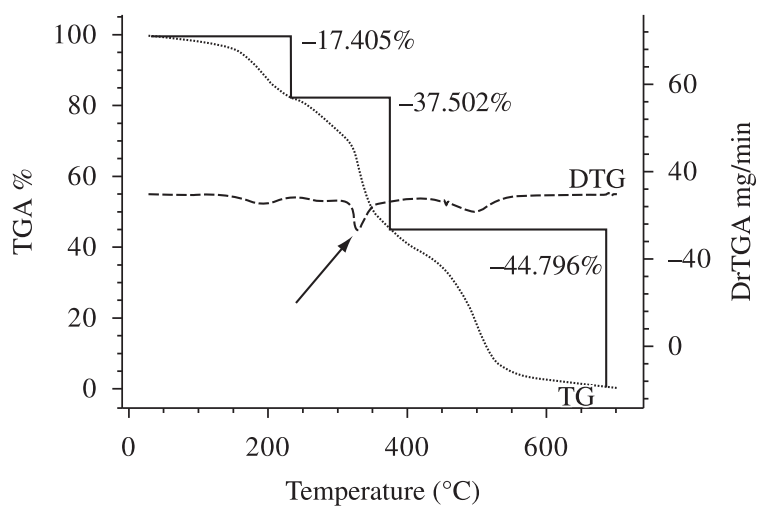

(c)

Figure 8. TGA signature for a) pure epoxy, b) epoxy + 5 wt. (\%) nanoclay, c) epoxy +3 wt. (\%) graphene nanosheets.

was around $41 \%$ for the nanoparticles/epoxy systems. At $600{ }^{\circ} \mathrm{C}$, the remaining mass for the graphene nanosheets/epoxy system was $4.10 \%$, while for the nanoclay/epoxy and epoxy ones the residual mass was close to $1.56 \%$. It seems that graphene nanosheets formed the most efficient barrier against mass loss. As described by Gilman ${ }^{31}$, intercalated nanostructures usually lead to higher mass loss when compared against exfoliated ones. For the nanoclay system, the nanostructures formed are mainly in the intercalated form as described by Ávila et al. ${ }^{32}$, while graphene nanosheets where dispersed in an exfoliated configuration. As stated by Leszczyńska and co-workers ${ }^{32}$, exfoliated nanostructures guide to a decrease on permeability that can be associated to char formation which hinders the out-diffusion of the volatile decomposition products. Moreover, the char acts as an insulator and mass transport barrier and therefore reduced the mass loss rate and improved flammability and thermal stability.

As discussed by Yasmin et al..$^{33}$, these thermal barriers formed during fire exposure reduce the volatiles degradation and at same time serve as a shield against the heat flux. Furthermore, it can be also due to the nanoparticles reaction with the carbon fibers during the oxidation process. This hypothesis is corroborated by the decrease on unburned thickness with the increase in time as described in Figure 9. This thermal barrier seems to be more effective after 60 seconds when most of nanoparticles', i.e. nanoclay and graphene nanosheets, interphase described by Yasmin et al. ${ }^{33}$ was totally burned. Yasmin and co-workers stated that such interphase is created during the cure process as result of remaining nanoparticles' surface surfactants, the epoxy system chemical reactions associated to the carbon fibers oxidation. Furthermore, according to her, these large interphase regions have thermal and mechanical properties deteriorated. Finally, an error on char thickness measurement by image processing can be the reason for control samples (epoxy/carbon fibers) good performance at 90 seconds.

It is important to measure the burnt hybrid composite dynamic response to LVI tests. This is due to the composite loss of stiffness after intense heat exposure, such stiffness variation can be indirectly be detected as impact force variations $(\triangle \mathrm{F})$ when compared against undamaged composites. Such phenomenon can be called as "softening by fire", and it is also related to the ratio between the char layer and the undamaged layer. In this research a non-dimensional parameter called $\lambda$ is defined as Equation 1:

$$
\lambda=\left(\frac{d-d_{c}}{d}\right)
$$

where $d_{\mathrm{c}}$ is the char layer and $\mathrm{d}$ the undamaged layer.

In the present model, the fiber reinforcement in the laminate decomposes following an exponential function as described in Feih et al. ${ }^{34}$. Mathematically we have (Equation 2),

$$
k=C_{1} e^{C_{2} t}
$$

where $C_{1}$ and $C_{2}$ are experimental constants, $t$ is the period of fire exposure at a fixed temperature degradation. The fiber decomposition

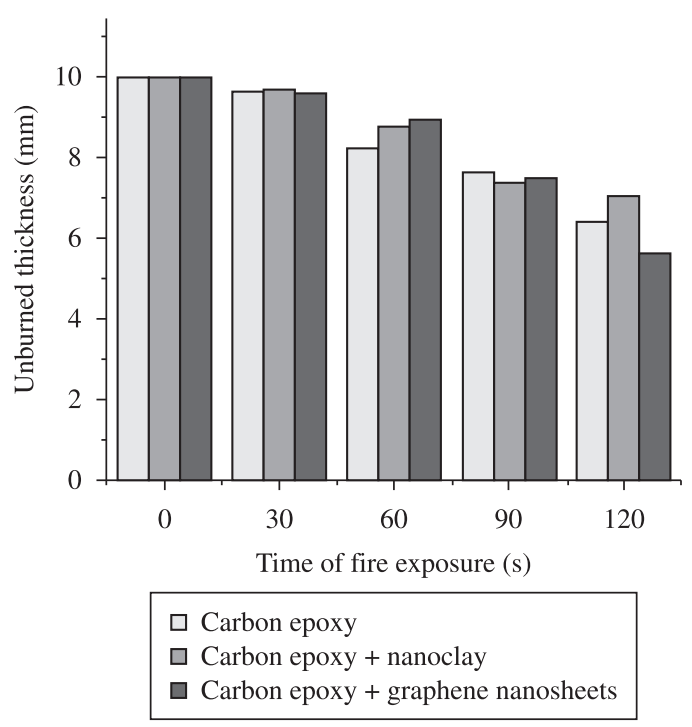

Figure 9. Plate plots: unburned thickness. 
coefficient $(\eta)$ describes the rate of strength loss as a function of time. Such parameter can be interpreted as a macroscopic representation of the carbon fibers degradation by oxidation. Note that, Equation 2 must be obtained for an isothermal condition. According to Feih and co-workers ${ }^{34}$ the degradation of epoxy systems can be generally represented by an autocatalytic radical type reaction (Equation 3), or

$$
\frac{d \alpha}{d t}=K_{0} e^{-E / R T} \alpha^{m}[1-\alpha]^{n} \text { where } \alpha=\left(\frac{m_{i}-m(t)}{m_{i}-m_{f}}\right)
$$

where $K_{0}$ and $\mathrm{E}$ are the rate constant and activation energy of the decomposition reaction, respectively. Note that these constants must be measured by thermo gravimetric analysis (TGA). $R$ is the universal gas constant, and $m_{\mathrm{i}}$ is the initial mass, $m$ is the mass at time $t$, and $m_{\mathrm{f}}$ is the final mass. The mechanical properties loss at a fixed time can finally described as (Equation 4),

$$
\psi=\left[\tanh \left(C_{1} e^{c_{2} t}\right)\right] \frac{d \alpha}{d t}
$$

Table 1. Comparison experiments x model.

\begin{tabular}{ccccr}
\hline ID & $\begin{array}{c}\text { Time* } \\
(\mathrm{s})\end{array}$ & $\begin{array}{c}\text { Measured peak } \\
\text { force }(\mathrm{KN})\end{array}$ & $\begin{array}{c}\text { Predicted peak } \\
\text { force }(\mathrm{KN})\end{array}$ & $\begin{array}{r}\triangle \mathrm{F} \\
(\%)\end{array}$ \\
\hline $\mathrm{CE}$ & 0 & 5.3860 & 5.3860 & 0.00 \\
& 30 & 4.8849 & 5.2403 & -7.27 \\
& 60 & 4.7254 & 5.0921 & -7.76 \\
& 90 & 4.0419 & 4.3661 & -8.02 \\
& 120 & 3.4193 & 3.7554 & -9.83 \\
$\mathrm{CC}$ & 0 & 5.3600 & 5.3600 & 0.00 \\
& 30 & 4.8977 & 5.2547 & -7.29 \\
& 60 & 4.8318 & 5.1909 & -7.43 \\
& 90 & 4.1133 & 4.4181 & -7.41 \\
& 120 & 3.8190 & 4.1359 & -8.29 \\
$\mathrm{CG}$ & 0 & 5.3873 & 5.3873 & 0.00 \\
& 30 & 4.9994 & 5.3364 & -7.76 \\
& 60 & 5.2276 & 5.5720 & -6.59 \\
& 90 & 4.2891 & 4.5999 & -7.23 \\
& 120 & 3.0911 & 3.4512 & -11.65 \\
\hline
\end{tabular}

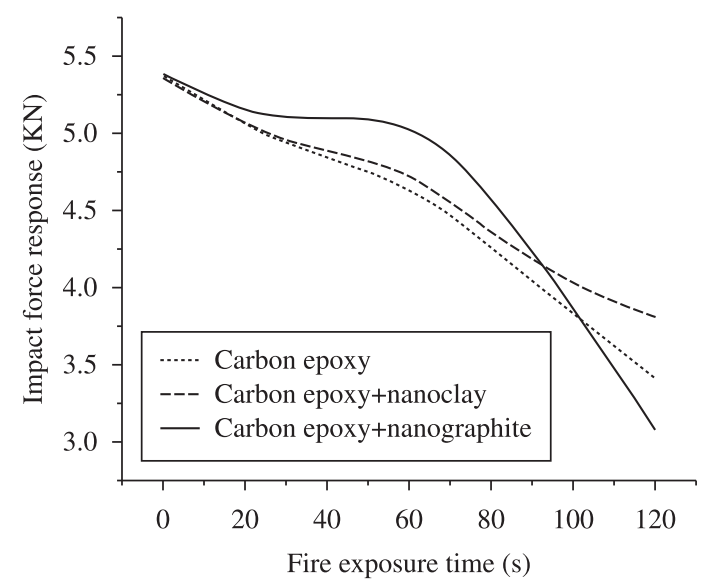

Figure 10. Composite's softening due to heat exposure.
Note that matrix and fiber degradation are taking into consideration. Furthermore, the softening parameter $(\psi)$ correlates the composite rate of degradability, as function of temperature and time, with mechanical properties. For the present case, the softening by fire effect can be defined as a decrease into the plate's force response to low velocity impact due to loss of stiffness and strength. A modification Mouritz's two-layer model can be represented as follows (Equation 5),

$$
F(t, T) \approx \lambda F\left(t, T_{A M B}\right)+\left(\frac{d_{c}}{d}\right) F\left(t, T_{A M B}\right) \psi=F\left(t, T_{A M B}\right)\left[\lambda+\left(\frac{d_{c}}{d}\right) \psi\right]
$$

where the second term of (Equation 5) is the char layer contribution to the overall impact force response.

Table 1 shows the softening effect due to the matrix degradation. The char layer thickness is also listed in Table 1 , as well as the mechanical reaction parameter $(\lambda)$. As described in Table 1 , the nanoclay addition to the nanocomposites seems to be more effective as $\lambda$ is higher for all conditions, but the 90 second. This discrepancy can be attributed to uncertainties during the optical image correlation used to measure the unburned/burnt thicknesses.

Figure 10 shows the material softening trend as function of time of heat exposure. As it can be noticed the turning point, for the epoxy/graphene nanosheets system, is around 90 seconds. The addition of graphene nanosheets also allows the formation of a thermal barrier and consequently an increase on the surface temperature. This increase on temperature can raise the resin burn rate, thus reducing the unburned layer thickness. At high temperature $\left(>700{ }^{\circ} \mathrm{C}\right)$, the graphene nanosheets etching process somehow lead to an increase fiber oxidation and consequently loss on stiffness. Notice although the TGA results indicates a better performance for the epoxy/graphene nanosheets system, as discussed by Feih et al. ${ }^{34}$, the matrix thermal stability is also dependent of the heating hate. For such high heat rate, the nanoclay addition seems to be a better option. The nondimensional parameter $(\lambda)$ seems to be able to capture the matrix degradation effect into mechanical properties.

\section{Conclusions}

It seems that the addition of nanoparticles, especially nanoclay and graphene nanosheets, to polymeric matrix carbon fiber composites offers these materials the opportunity of being considered as fire resistant materials. Thermo gravimetric analysis (TGA) indicates an average decrease on mass loss around $41 \%$ with the addition of small amount of nanoparticles. For short beam samples exposed to $800 \mathrm{KW} \cdot \mathrm{m}^{-2}$ heat flux for a period of time up to 120 seconds, the addition of nanoparticles (nanoclay and graphene nanosheets) increased the unburned thickness from $0.16 \mathrm{~mm}$ (original) to 2.63 and $2.74 \mathrm{~mm}$, respectively. When the two-dimensional (plates) samples were tested, the improvement on heat performance was reduced. The unburned thickness improved close to $10 \%$ with the presence of nanoclay. The addition of graphene nanosheets leads to a decrease in unburned thickness of $12.8 \%$.

Using SEM analysis, it was observed that when the nanocomposites were subjected to a large heat flux, nanoparticles remained trapped inside the char layers. This indicates that these nanoparticles can still act effectively as thermal barrier even after the resin was completed burnt. The post-fire low velocity impact tests indicated the impact resistance degraded as a function of heat exposure. However, the addition of nanoclay leads to an increase on impact peak force of $11.69 \%$. The carbon oxidation could be the main cause of the increase on impact peak load is lower than expected, only $6.72 \%$. The model predictions are overestimated by approximately $8 \%$. Even though, it can be a good tool for composites design. 


\section{Acknowledgments}

The first author would like to acknowledge the financial support provided by the Brazilian Research Council (CNPq) under grants 300826/2005-2 and 472213/2007-5. We also would like to express a special gratitude to the Center of Microscopy and Microanalysis of Universidade Federal de Minas Gerais for the usage of the SEM.

\section{References}

1. Ulven CA and Vaidya UK. Impact response of fire damaged polymerbased composite materials. Composites Part B (Kidlinton), 2008; 39(1):92-107.

2. MouritzAP and Mathys Z. Post-fire mechanical properties of marine polymer composites. Composite Structures (Oxford), 1999; 47(7):643-653.

3. Mouritz AP and Mathys Z. Post-fire mechanical properties of glassreinforced polyester composites. Composites Science and Technology (Barking), 2001; 61(4):475-490.

4. Mouritz AP. Simple models for determining the mechanical properties of burnt FRP composites. Materials Engineering A (New York), 2003; 359(2):237-246.

5. Mouritz AP, Mathys $\mathrm{Z}$ and Gardiner CP. Thermomechanical modelling the fire properties of fibre polymer composites. Composites Part B: Engineering (Kidlinton), 2004; 35(6-8):467-474.

6. Gibson AG, Wu Y-S, Evans JT and Mouritz AP. Laminate theory analysis of composites under load in fire. Journal of Composite Materials (Lancaster), 2006; 40(7):639-658.

7. Kim J-S, Jeong J-C, Cho SH and Seo S-I Fire resistance evaluation of a train carbody made of composite material by large scale tests. Composite Structures (Oxford), 2008; 83(2):295-303.

8. Hernangil A, Rodrigues M, Leon LM, Ballestero J and Alonso JR. Experimental design of fire retardant formulations: smc low profile formulations. Journal of Composite Materials (Lancaster). 1998; 32(23):2120-2155.

9. Guo G and Asaro RJ. Designing polymer matrix composite panels for structural integrity in fire. Composite Structures (Oxford), 2008; 84(3):300-309.

10. Guo G, Park CB, Lee YH, Kim YS and Sain M. Flame retarding effects of nanoclay on wood-fiber composites. Polymer Engineering Science (Stanford), 2007; 47(3):330-336.

11. Morgan AB. Flame retarded polymer layered silicate nanocomposites: a review of commercial and open literature systems. Polymer Advanced Technology (Malden), 2006; 17(4):206-217.

12. Koo JH. Polymer nanocomposites: processing, characterization and applications. New York: McGraw-Hill; 2006.

13. Li F, Jianhuai W, Jiongtain L, Binguo W and Shuojiang S. Preparation and fire retardancy of antimony oxide nanoparticles/mica composition. Journal of Composite Materials (Lancaster), 2007; 41(7):1487-1497.

14. Morgan AB, Chu L-L, Harris, JD. flammability performance comparison between synthetic and natural clays in polystyrene nanocomposites. Fire Materials (Malden), 2005; 29(4):213-229.

15. Wang Y-G, Zhou B-L and Wang Z-M. Oxidation protection of carbon fibers by coating. Carbon (Elmsford) 1995; 33(4):427-433.

16. Keller TM. Oxidative protection of carbon fibers with poly(carboranesiloxane-acetylene). Carbon (Elmsford), 2002; 40(2):225-229.
17. Hatta H, Takuya A, Yasuo K and Toshio Y. High-temperature oxidation behavior of SiC-coated carbon fiber-reinforced carbon matrix composites. Composites Part A (Kidlinton), 1999; 30(4):515-520.

18. Jacobson NS and Curry DM. Oxidation microstructure studies of reinforced carbon/carbon. Carbon (Elmsford), 2006; 40(6):1142-1150.

19. Jiqiao L, Chen T, Huang B, Shi G and Xiong X. Influence of the pore structure of carbon fibers on the oxidation resistance of $\mathrm{C} / \mathrm{C}$ composites. Carbon (Elmsford), 2006; 40(2):615-637.

20. Zhang S, Horrocks AR, Hull R and Kandola BK. Flammability, degradation and structural characterization of fibre-forming polypropylene containing nanoclay-flame retardant combinations. Polymer Degradation and Stability (Essex), 2006; 91(4):719-725.

21. Liu L, Ryu S, Tomasik MR, Stolyarova E, Jung N, Hybertsen MS, et al. Graphene oxidation: thickness-dependent etching and strong chemical doping. Nano Letters (Washington, DC), 2008; 8(7):1965-1970.

22. Ávila AF, Donadon LV and Duarte HV. Modal analysis on nanoclay epoxy-based fiber-glass laminates. Composite Structures (Oxford), 2008; 83(3):324-333.

23. Bahramian AR, Kokabia M, Famili MHN and Beheshty MH. Ablation and thermal degradation behaviour of a composite based on resol type phenolic resin: processmodeling and experimental. Polymer (Oxford), 2006; 47(10):3661-3673.

24. Ávila AF, Koo JH and Bracarense, AQ. An investigation on nanocomposites under intense heat conditions. In Proceedings of the $23^{\text {th }}$ Technical Conference of the American Society for Composites; 2008; Memphis, USA.

25. American Society for Testing and Materials. Standard test method for impact resistance of flat, rigid plastic specimens by means of a falling dart (tup or falling mass). In Annual Book of ASTM Standards. West Conshohocken: ASTM; 2001. p. 628-627.

26. Found MS, Howard IC and Paran AP. Interpretation of signals from dropweight impact tests. Composite Structure (Oxford), 1998; 42(3):353-363

27. Ávila AF, Soares MI and Silva Neto A. A study on nanostructured laminated plates behavior under low-velocity impact loadings. International Journal of Impact Engineering (Oxford), 2007; 31(1):28-41.

28. Kourtides DA. Thermal and flammability characterization of graphite composites. Journal of Fire Science (Lancaster), 1986; 4(6):397-428.

29. Schartel B, Bartholmai M and Knoll U. Some comments on fire retardancy mechanisms in polymer nanocomposites. Polymers for Advanced Technologies (Malden), 2006; 17(7):772-777.

30. Hussain F, Hojjati M, Okamoto M and Gorga RE. Polymer-matrix nanocomposites, processing, manufacturing, and application: an overview. Journal of Composite Materials (Lancaster), 2006; 40(14):1511-1575.

31. Gilman, JW. Flammability and thermal stability studies of polymer layered-silicate (clay) nanocomposites. Applied Clay Science, 1999; 15(1):31-49.

32. Leszczynska A, Njuguna JK, Pielichowskia K and Banerjee JR. Polymer/ montmorillonite nanocomposites with improved thermal properties. Thermochimica Acta (Amsterdam), 2007; 453(2):75-96.

33. Yasmin A, Luo J-J and Daniel IM. Mechanical and thermal behavior of clay/epoxy nanocomposites. Composites Science and Technology (Barking), 2006; 66(7):1182-1189.

34. Feih S, Mathys Z, Gibson AG and Mouritz AP. Modelling the compression strength of polymer laminates in fire. Composites Part A (Kidlinton), 2007; 38(11):2354-2365. 